\title{
First ground-based observations of sprites over southern Africa
}

Stanislaus Nnadih ${ }^{1,2}$ iD

Mike Kosch $3,4,5$

Peter Martinez ${ }^{2}$

Jozsef Bor ${ }^{6}$

\section{AFFILIATIONS:}

${ }^{1}$ African Regional Centre for

Space Science and Technology

Education, lle Ife, Nigeria

${ }^{2}$ SpaceLab, Department of

Electrical Engineering, University

of Cape Town, Cape Town,

South Africa

${ }^{3}$ Space Science Division,

South African National Space

Agency, Hermanus, South Africa

${ }^{4}$ Department of Physics,

University of Western Cape,

Cape Town, South Africa

${ }^{5}$ Physics Department,

Lancaster University, Lancaster,

United Kingdom

${ }^{6}$ Research Centre for Astronomy and Earth Science, Hungarian

Academy of Science,

Budapest, Hungary

\section{CORRESPONDENCE TO:}

Stanislaus Nnadih

\section{EMAIL:}

Nndsta001@myuct.ac.za

\section{DATES:}

Received: 29 Aug. 2017

Revised: 19 Jan. 2018

Accepted: 06 June 2018

Published: 11 Sep. 2018

\section{KEYWORDS:}

lightning discharge; mesosphere; atmosphere; thunderstorm

\section{HOW TO CITE:}

Nnadih S, Kosch M, Martinez

P, Bor J. First ground-based observations of sprites over southern Africa. S Afr J

Sci. 2018;114(9/10), Art.

\#4272, 6 pages. https://doi.

org/10.17159/sajs.2018/4272

\section{ARTICLE INCLUDES: \\ $\checkmark$ Supplementary material \\ $\times$ Data set}

\section{FUNDING:}

National Research Foundation (South Africa)

\section{(C) 2018. The Author(s).}

Published under a Creative

Commons Attribution Licence.
Sprites are the optical signatures of electrical discharges in the mesosphere triggered by large lightning strikes associated with thunderstorms. Since their discovery in the late 1980s, sprites have been observed extensively around the world, although very few observations of sprites from Africa have been documented in the literature. In this paper, we report the first ground-based recorded observations of sprites from South Africa. In 2 out of the 22 nights of observations (11 January and 2 February 2016), about 100 sprite elements were recorded from Sutherland in the Northern Cape, comprising different morphologies (carrot (55\%), carrot/column (11\%), unclassified (21\%), column (13\%)). The sprites were triggered by positive cloud-to-ground lightning strikes, which had an average peak value of $\sim 74 \mathrm{kA}$ and were observed at distances from $\sim 400 \mathrm{~km}$ to $800 \mathrm{~km}$. The estimated charge moment change of the lightning discharges associated with these events was in agreement with the threshold for dielectric breakdown of the mesosphere and correlates well with the observed sprite brightness.

\section{Significance:}

- The first ground-based recording of sprite events over southern Africa.

- It is suggested that the intensity of the events is proportional to the lightning stroke current.

\section{Introduction}

Anecdotal accounts of sporadic brief optical emissions appearing above thunderstorms have been found in the scientific literature for many years. ${ }^{1-4}$ Such phenomena were also noted by South African observers. For instance, in 1937, Malan ${ }^{5}$ reported seeing a different kind of lightning in Johannesburg, at an approximate altitude of $50 \mathrm{~km}$. He noted:

On the evening of 2 January 1937, there was a long cloud bank about $100 \mathrm{~km}$ to the northeast... During the span of an hour and a half, a long and weak streamer of reddish hue appeared about ten times in the upper cloud simultaneously with a weak illumination of the same cloud. I assume the weak illumination was due to cloud-to-ground discharge (CG) behind the hills.

These anecdotal pieces of evidence were not corroborated until 1989, when Prof. J. Winckler's group accidentally discovered a flash of light, illuminating the sky above a distant thunderstorm. ${ }^{6}$ This discovery sparked interest in such phenomena and their potential dangers to crewed spacecraft during take-off or landing. This interest later led to the discovery of all other optical phenomena in the stratosphere and mesosphere (ELVES, blue jets, halos, and gigantic jets), which were collectively termed transient luminous events. ${ }^{7,8}$

Sprites are short-lived optical phenomena occurring above large thunderstorms. They are often described as large electrical discharges in the mesosphere. ${ }^{9}$ When observed with a high-speed camera, ${ }^{10,11}$ they appear to move downwards (for positive streamers) and then upwards (for negative streamers) with a speed in excess of $10^{7} \mathrm{~m} / \mathrm{s}$. They are mostly associated with positive cloud-to-ground (+CG) lightning strikes, which transfer a positive charge to the ground ${ }^{12-14}$, although some studies have revealed that, on rare occasions, negative cloud-to-ground (-CG) lightning strikes can also initiate sprites ${ }^{15,16}$.

Sprite research has been actively conducted in the USA, Asia, Europe, South America and Australia. ${ }^{12,17-20}$ Sprites have also been successfully studied from the International Space Station over central Africa, northern Australia and South America, as well as over the Pacific and Indian Oceans. ${ }^{21-23}$ These studies have led to many discoveries (e.g. the ELF radiation produced by the electrical current in sprites ${ }^{24}$ and the energy deposited by large sprites is of the order $1 \mathrm{GJ} /$ event $^{25}$ ), which have been documented in numerous scientific publications describing the sprite phenomenon and its dynamics ${ }^{26-28}$.

Some of these studies suggest that, apart from contributing to the global electric circuit, sprite initiation can also affect the chemistry of the middle atmosphere by altering the composition of the oxides of nitrogen and hydrogen. These chemical changes could have an impact on the heating or cooling of this region ${ }^{29}$ or interfere with longdistance communication through the lower ionosphere ${ }^{30}$. Thus, it is important to determine the occurrence rate and geographical distribution of sprites and the energy associated with these events in order to verify these assertions. The global occurrence rate for sprites has been estimated to be 1-3 sprite events every minute. . $5,31-33^{2}$

Despite being a lightning-rich continent ${ }^{34}$, there is currently no active ongoing sprite-related research in Africa, although there were a few observations carried out in West Africa during the 2006 African Monsoon Multidisciplinary Analysis campaign ${ }^{35}$. In this paper, we describe the observations that led to the first ground-based recording of sprites over southern Africa. 


\section{Observations}

\section{Instrumentation}

The optical instrument used for the observations reported in this paper was a Watec $910 \mathrm{Hx}$ camera, which has a $40-\mathrm{ms}$ time resolution and was operated with a 80-ms temporal resolution in order to improve the signal-to-noise level. This camera is a standard low-light commercially available monochromatic charge-coupled device (CCD) camera (Figure 1), which is commonly used by observers of transient luminous events in Europe, the USA and Israel. 36,37 The CCD detector array of 352 by 288 pixels was oriented with the long axis of the detector in the horizontal plane. The camera was fitted with a $8.0 \mathrm{~mm} \mathrm{~F} / 1.4$ lens. The field of view on the detector was $35.3^{\circ}$ horizontal and $26.6^{\circ}$ vertical, as determined by reference to known background stars on the image. This gives a horizontal/vertical angular resolution of $0.10 / 0.09^{\circ}$ per pixel. The camera records video frames with 8-bit resolution.

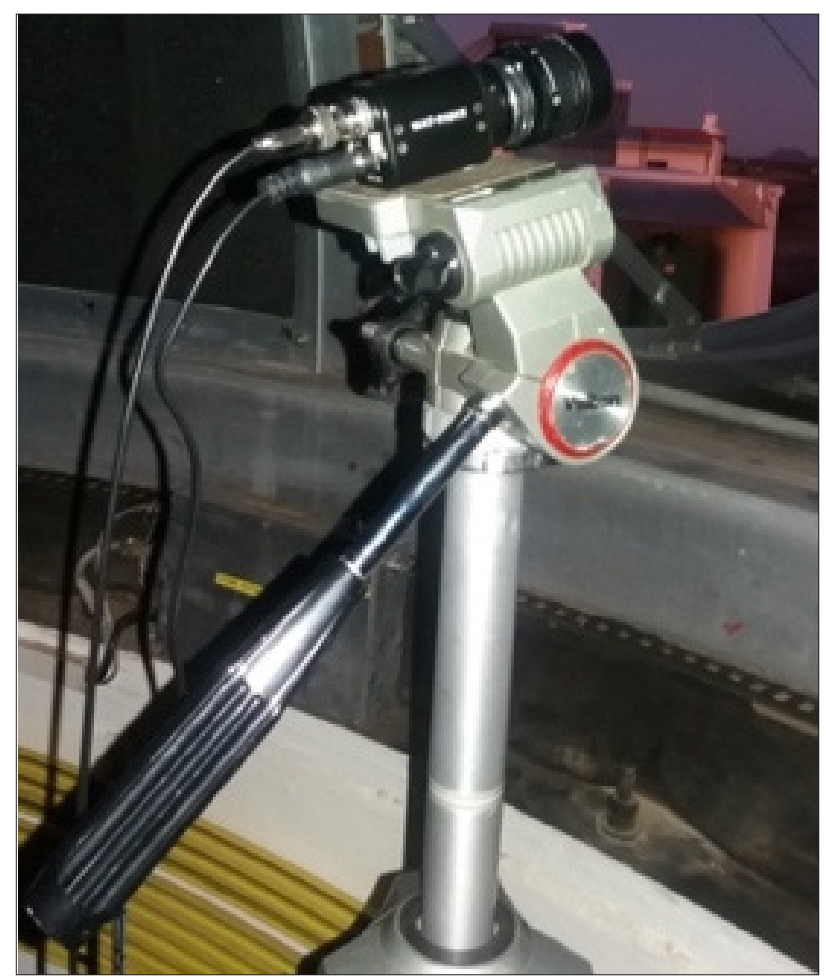

Figure 1: The camera used during the sprite observations.

The camera was connected through a video digitiser (Pinnacle Dazzle) to a computer that ran the Sonotaco sprite capture software version 2 (http://sonotaco.com/soft/e index.html). The software has a triggering mechanism that allows it to read out the CCD continuously, but only stores data according to the detection threshold that was set by the operator. To ensure the accuracy of the timing system, the computer was connected to the Network Timing Protocol server of the South African Astronomical Observatory (SAAO) in Sutherland, which has a time resolution of approximately $100 \mu \mathrm{s}$.

\section{Camera pointing angle}

Previous studies have shown that sprites occur within the mesosphere at an altitude range of $\sim 40-90 \mathrm{~km}$, with maximum brightness at an altitude of $\sim 68 \mathrm{~km}$ lasting several milliseconds. ${ }^{38,39}$ Thus, it was necessary to point the camera at the right elevation for a successful observation. Equation 1 relates the pointing elevation angle for the camera to different distances and altitudes for a given viewing geometry as shown in Kosch et al. ${ }^{40}$

$\tan [90-\theta]=\left\{(h+R e) \sin \left[\frac{d}{R e}\right]\right\} /\left\{(h+R e) \cos \left[\frac{d}{R e}\right]-R e\right\}$, Equation 1

where $\theta$ is the observation elevation angle; $h$ is the altitude above ground, $\mathrm{Re}=6370 \mathrm{~km}$ and is the radius of the earth, and $\mathrm{d}$ is the distance of the storm from the camera along a great circle arc.
Thus, for $\mathrm{h}=100 \mathrm{~km}$ (lower boundary of the nighttime ionosphere):

$$
\begin{aligned}
& \mathrm{d}=100 \mathrm{~km}=>\theta=44.3^{\circ} \\
& \mathrm{d}=200 \mathrm{~km}=>\theta=25.5^{\circ} \\
& \mathrm{d}=300 \mathrm{~km}=>\theta=17.0^{\circ} \\
& \mathrm{d}=400 \mathrm{~km}=>\theta=12.1^{\circ}
\end{aligned}
$$

The orientation of the camera (azimuth and elevation angle) was determined during the analysis, by identifying the stars recorded in the image, which can be done to single-pixel accuracy.

\section{Observation technique}

This instrument was set up at the SAAO in Sutherland, Northern Cape, South Africa (20.8117 E, 32.3872 S) and operated during the seasonal peak lightning period in southern Africa from December 2015 to February $2016 .{ }^{41}$ SAA0 was an ideal location for such observations because of its altitude $(1798 \mathrm{~m})$ above sea level. This location was also chosen because of its clear dark night sky that is free of light pollution from cities, which allows the optical instrument to observe any transient luminous events up to a $900 \mathrm{~km}$ radius from SAAO.

When to operate the camera and where to point it was determined in near real time by observing storm activities over southern Africa using Meteosat infrared imagery, which is made available in near real time by EUMETSAT (http://www.eumetsat.int/website/home/index.html). This information was also complemented by lightning forecast data from the SAT24 website (http://en.sat24.com/en/forecastimages/afrika/ forecastlightning). The Meteosat infrared imagery is automatically updated every $15 \mathrm{~min}$, making it possible to track a storm almost in real time. The infrared band was chosen to enable us to identify the brightest part of the cloud because the brighter the cloud, the colder and the more likely it is to produce lightning strokes. ${ }^{42}$
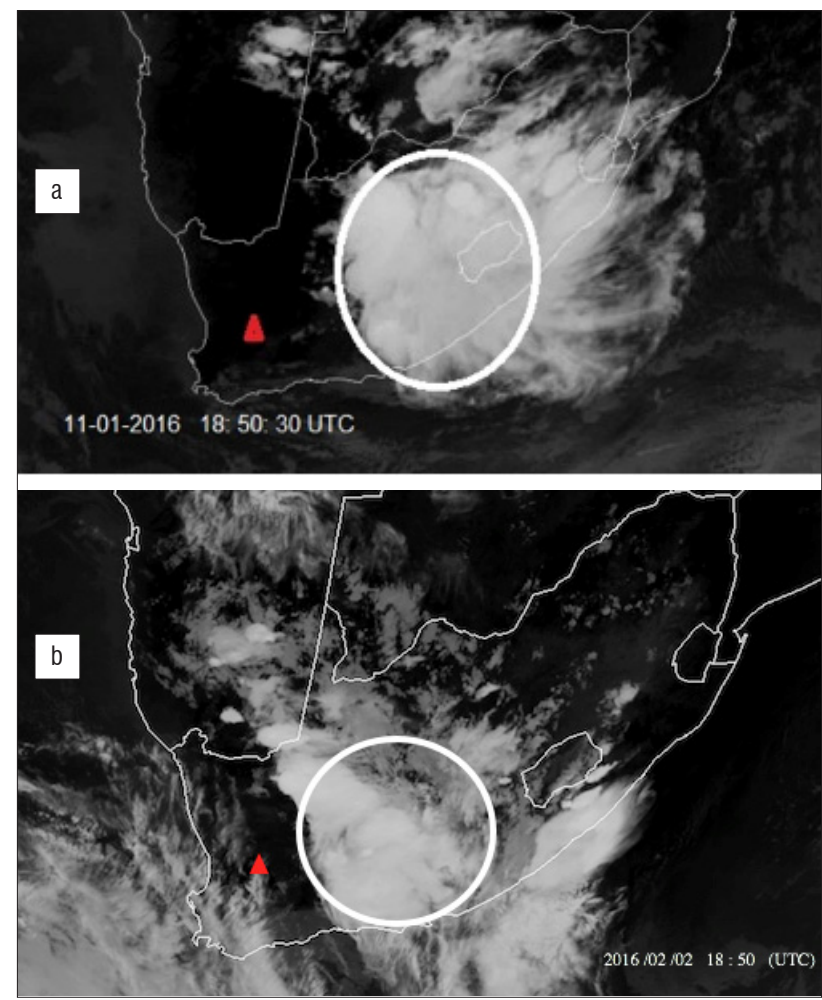

Figure 2: Meteosat infrared imagery showing the thunderstorms tracked on the nights of (a) 11 January 2016 and (b) 2 February 2016. The triangle shows the observation point. The circle shows the storm, which was $\sim 350 \mathrm{~km}$ from the observation point in (a) and $\sim 280 \mathrm{~km}$ in (b). 
For each night of sprite observation, the Meteosat imagery over southern Africa was examined for storm activity to select the camera viewing azimuth. For thunderstorms beyond $400 \mathrm{~km}$ from the observation point, an elevation angle of $15^{\circ}$ was used to avoid pointing the bottom edge of the camera's $26.6^{\circ}$ vertical field of view below the horizon and imaging lightning strokes that cause false detections. As most of the storms observed during the campaign occurred beyond $250 \mathrm{~km}$ away, the value used for the elevation angle was set to $\sim 15^{\circ}$, whereas the azimuth was regularly adjusted based on the nightly lightning strike forecasts. Figure 2 shows some examples of the Meteosat imagery used. As the storm weakened, moved or became more active in another area, the camera was manually adjusted to point in the direction of the most intense lightning activity. Observations of a particular storm typically lasted several hours. Depending on the number of cells that make up a cumulonimbus cloud, an average active storm can remain energetic up to $3 \mathrm{~h}$ before weakening (Lennard C 2016, oral communication, January 15).

\section{Results}

On 2 of the 22 nights of observations, a total of 54 video frames comprising $\sim 100$ sprites were recorded. By visual inspection, these events exhibit different shapes/structures, which include carrot (55\%), column (13\%), carrot/column (11\%) and unclassified $(21 \%)$. The naming of these groups depends on the final structure of the emission as described by Bor ${ }^{43}$. Figure 3 shows an example of the different types of sprites recorded during these observations, and Table 1 presents the structural statistics of all the events.

Table1: Structural statistics of recorded events

\begin{tabular}{l|c|c}
\multicolumn{1}{c|}{ Sprite type } & Distribution (\%) & Links to video frames of the events \\
\hline Carrot & 55 & 20160111_18:53:49.4 \\
\hline Carrot/column & 11 & 20160111_19:17:09.8 \\
\hline Unclassified & 21 & 20160111_19:49:19.7 \\
\hline Column & 13 & 20160111_19:38:32.5 \\
\hline
\end{tabular}

\section{Data analysis}

The sprite images were superimposed on the star catalogue of the Sonotaco sprite analyser software (http://sonotaco.com/soft/e_index. $\mathrm{html}$ ) version 2. This software uses the star coordinate data that were extracted from the SKY2000 Master Catalogue, version 4. The stars on the sprite images were manually aligned to the stars in this catalogue to within single-pixel resolution to estimate the azimuth, elevation and location (longitude and latitude) of each of these sprite elements. a

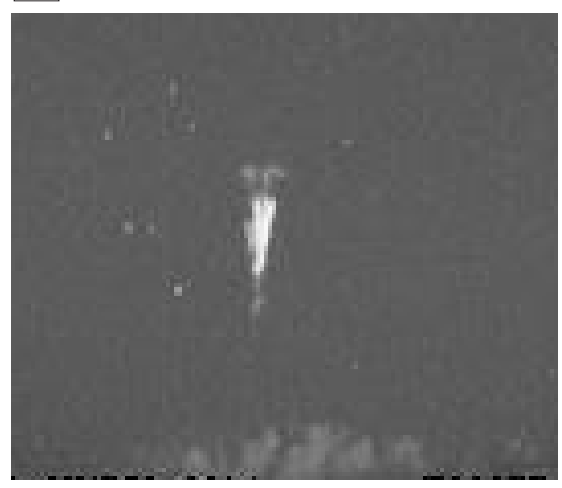

c

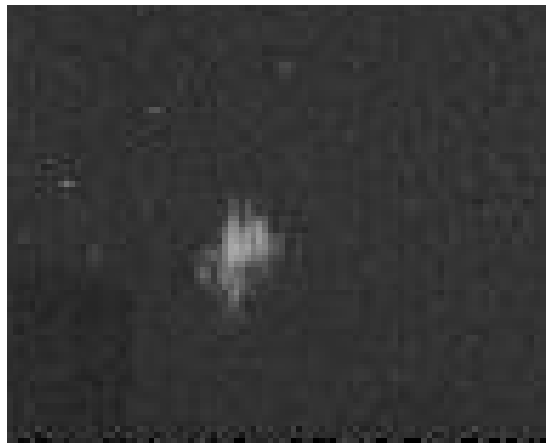

$\mathrm{b}$

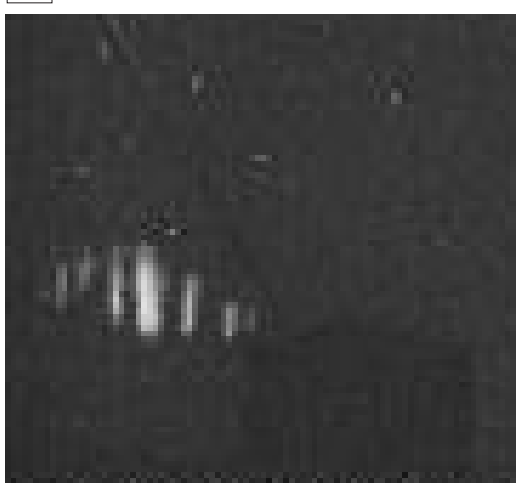

d

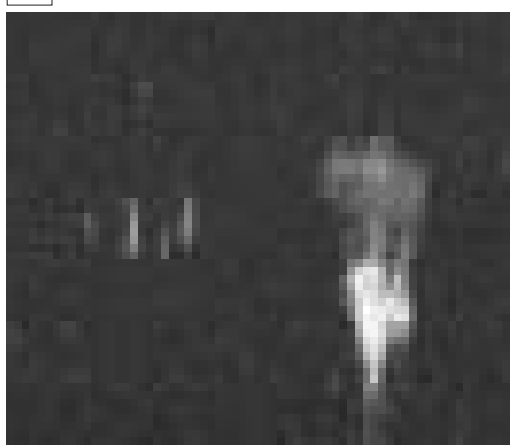

Figure 3: Some examples of the sprite elements recorded on 11 January 2016 with variable zoom: (a) carrot-shaped sprite observed at 18:53:49.4 UTC, (b) seven column-shaped sprites observed at 19:38:32.5 UTC, (c) unclassified sprite observed at 20:08:03.3 UTC, (d) two-carrot/four-columnshaped sprite observed at 19:17:09.8 UTC. Panel (a) shows the very first sprite image that was recorded over southern Africa. The dark square in the bottom left in panels (b)-(d) is a telescope dome in the foreground. The bright spots are stars. 
The azimuth uncertainty when locating sprites using simple geometry depends on the distance from the camera to the sprite. For a typical range of $600 \mathrm{~km}$ and horizontal pixel resolution of $0.1^{\circ}$, the azimuthal uncertainty translates to $\pm 0.5 \mathrm{~km}$ per pixel. The distance (d) is determined from Equation 1 by measuring the elevation angle $(\theta)$ to the top of the sprite and assuming an initiation altitude (h) of $85 \mathrm{~km} .{ }^{9,38,44}$ The range uncertainty consists of the star-fit image pixel jitter in the vertical direction (1-pixel, which is equivalent to $0.09^{\circ}$ ) and the sprite initiation altitude $(5 \mathrm{~km}) .^{12}$ Again, for a typical range of $600 \mathrm{~km}$, the uncertainty was $\pm 27 \mathrm{~km}$, which is dominated by the uncertainty in the sprite initiation altitude.

Archival lightning stroke data over South Africa were obtained from the South African Weather Service (SAWS). The SAWS operates a network of sensors that detect lightning strokes over South Africa. ${ }^{45}$ The system uses magnetic direction finding and time of arrival of the lightning stroke to determine the actual time and location of the lightning strokes in real time. For post-processing of the sprite events recorded during the observations at $80 \mathrm{~ms}$ (2 TV frames), the initiation timestamp on the images together with the coordinates retrieved from the Sonotaco sprite analyser software were compared with the lightning stroke data set from SAWS in position and time, with the assumption that sprites could be initiated within a $50 \mathrm{~km}$ distance from the parent lightning stroke $\mathrm{k}^{46,47}$ and within the $80 \mathrm{~ms}$ image temporal resolution.

\section{Distance estimation}

Sprites are believed to initiate at altitudes $\sim 85 \mathrm{~km}^{9,38,44}$ with maximum brightness around $68 \mathrm{~km}^{12}$. By measuring the elevation angle, we were able to estimate the distance between the source and observer. The viewing elevation angle was retrieved by star fitting the image frames to many corresponding reference stars in the catalogue. We then derived Equation 2 from Equation 1 in order to solve for the distance (d).

$d=\operatorname{Re}\left[\theta-\sin ^{-1}\left(\frac{R e \sin \theta}{h+R e}\right)\right]$

Equation 2

The results from this calculation show that most of the sprite events occurred approximately between $540 \mathrm{~km}$ and $680 \mathrm{~km}$ from the observation point. Where the sprites comprised several sprite events in a group, the distance was estimated from the centre of the group. The error in this estimate for one pixel offset in the horizontal and vertical direction was $\pm 5 \%$ of the average distance from the observation point.

\section{Sprite brightness estimation}

Sprite brightness was estimated by using the ImageJ software (https:// imagej.net/Welcome). We first averaged the scintillation effects of a star that was present in all the video frames of each captured sprite video clip. This step was done to obtain an average intensity value for the star $\left(\right.$ Star $\left._{\text {avg }}\right)$ because it has a constant brightness. We then applied a $7 \times 7$ median filter on all the individual TV frames containing sprites to remove the background stars (Figure 4). Next, we measured the brightness of an area (same height and width) with a sprite element and background sky (Sp+Sky) and also the brightness of two adjacent areas of the sky without sprite elements (Sky ${ }_{1}, \mathrm{Sky}_{2}$; marked '1', '2' on Figure 4b) and recorded their average $\left(S k y_{\text {avg }}\right)$. The essence of using the average was to minimise errors in the estimation of the sky background. Thereafter, we subtracted Sky ${ }_{\text {avg }}$ from Sp+Sky to estimate the sky-subtracted brightness of each sprite element $\left(\mathrm{Sp}_{\mathrm{bot}}\right)$. Finally, we normalised the sprite brightness $\left(\mathrm{Sp}_{\mathrm{bot}}\right)$ by dividing each of these values by the average brightness of the reference star $\left(\mathrm{Star}_{\text {avg }}\right)$. Because brightness is inversely proportional to the square of the distance, we finally divided each result by the square of its corresponding distance to the observation point. Supplementary table 1 shows a list of all the sprite events recorded on 11 January 2016, along with their corresponding parameters.

\section{Charge moment change estimation}

The charge moment change (CMC) is an important lightning metric for sprite studies that is not measured by the Lightning Detection Networks. It is defined as the product of the charge and the altitude from where these charges were lowered to the ground. ${ }^{48}$ Analogous to a capacitor, the amount of charge and its separation distance determines the voltage and it is the electric field generated by the charge displacement during a lightning strike that triggers sprites. The CMC data were obtained from the Schumann resonance station in Hungary (NCK; $47.62^{\circ} \mathrm{N}, 16.72^{\circ} \mathrm{E}$ ). This station is located $\sim 8947 \mathrm{~km}$ away from SAAO. The system records both the vertical electric field components $\left(E_{\mathrm{r}}\right)$ and the horizontal magnetic field components $\left(H_{\mathrm{NS}}\right.$ and $\left.H_{\mathrm{EW}}\right)$ associated with lightning strokes. ${ }^{49}$ The CMC associated with some of the sprite events was retrieved from the electric component of the parent lightning strokes as described in Huang et al. ${ }^{50}$ This analysis is simpler when observing the signals in the far field, hence Schumann resonance observations from lightning in South Africa were made in the northern hemisphere. Because of the relatively high noise level in the Schumann resonance system during these observations, only about $20 \%$ of the events that were observed were satisfactorily processed.

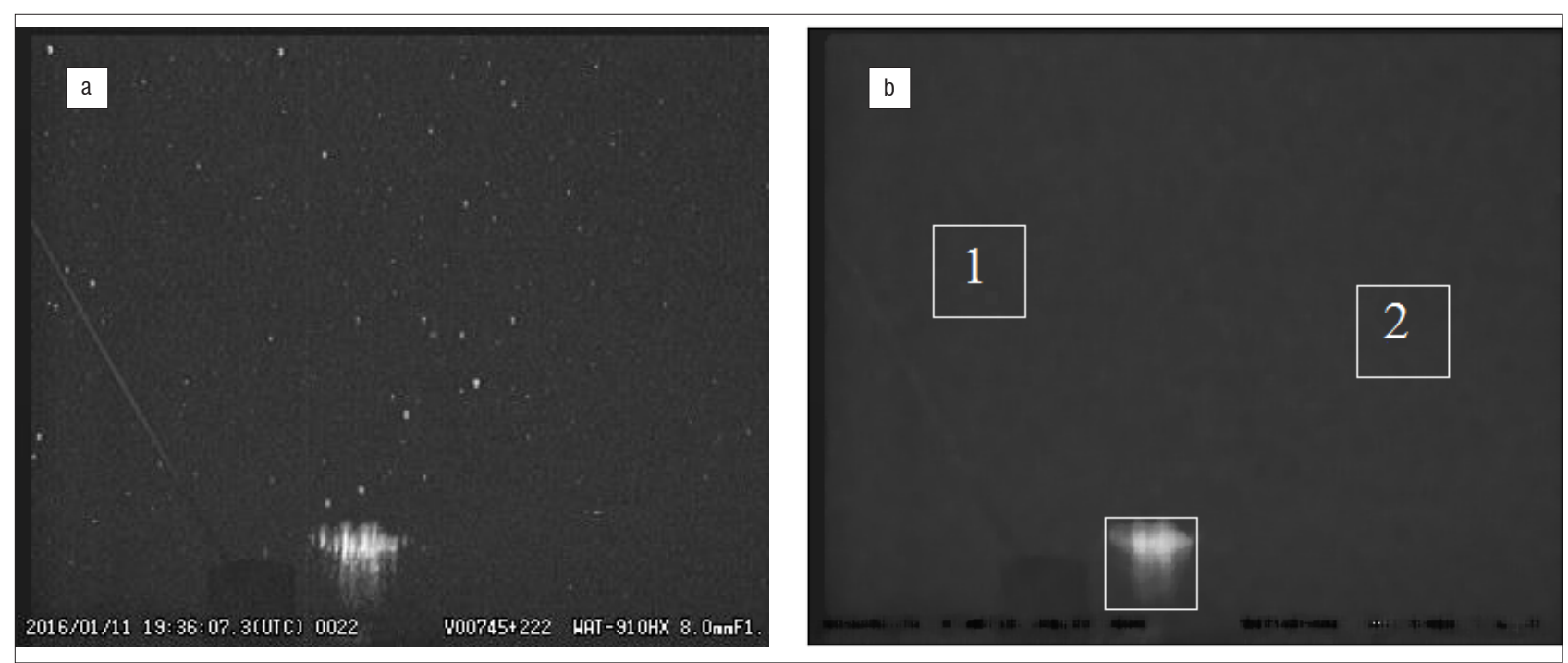

Figure 4: Sprite image (a) before and (b) after applying a $7 \times 7$ median filter to remove the background stars. The boxes marked ' 1 ' and ' 2 ' indicate the locations used to derive the sky backgrounds $\left(\mathrm{Sky}_{1}, \mathrm{Sky}_{2}\right)$. The average of these sky backgrounds was used to derive the sky-subtracted brightness of the sprite elements. 
The CMC associated with these processed events ranged from 900 C.km to $2000 \mathrm{C} . \mathrm{km}$. These values are consistent with the findings of earlier studies ${ }^{51,52}$ and were in agreement with the theoretical threshold (500-1000 C.km) for dielectric breakdown of the mesosphere ${ }^{35}$. Figure 5 shows the relationship between sprite brightness, as described above, and charge moment change for all events for which Schumann resonance data and their corresponding parent CG lightning strike were available (Supplementary table 1).

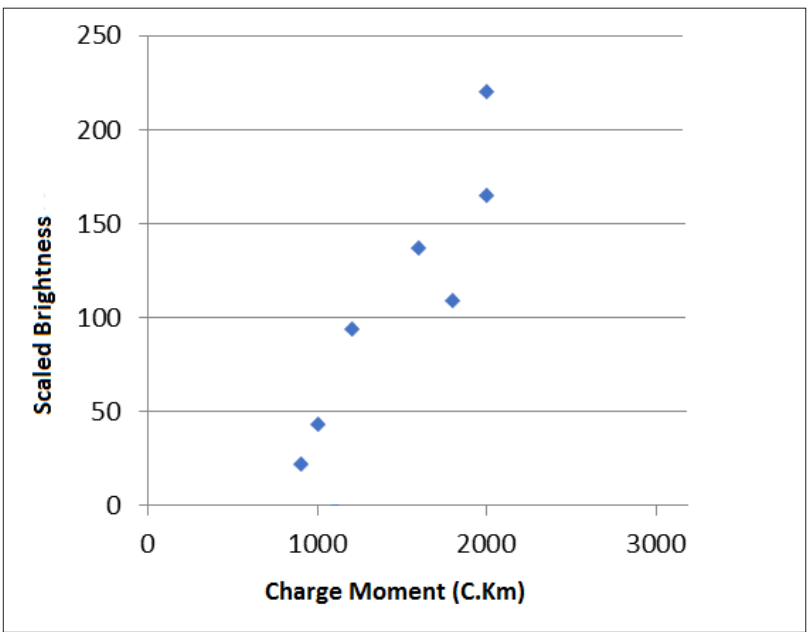

Figure 5: The relationship between the sprite luminosity and the charge moment of the lightning discharges for the events where Schumann resonance data and the parent cloud-to-ground lightning strike were available.

\section{Discussion}

As these were the first recorded ground-based images of sprites in southern Africa, we began our analysis with a simple visual inspection of our sprite images to compare them with images recorded in other parts of the world. This comparison showed that the various structures we recorded were approximately the same as those recorded elsewhere. Whilst the physical mechanism(s) that is responsible for the formation of the column and carrot-shaped sprites has been proposed by Qin ${ }^{53}$, the mechanism that is responsible for other structures of sprites remains poorly understood.

Our analysis also shows that, for the sprite events that were associated with their corresponding lightning strokes, the average lightning peak current associated with these sprite initiations was $\sim 74 \mathrm{kA}$, and that the maximum and minimum current values were $191 \mathrm{kA}$ and $11 \mathrm{kA}$, respectively. In all cases, the initiating lightning strikes were positive cloud-to-ground lightning strokes (+CGs). These values were derived from the lightning strike location data sets from the SAWS network. The average displacement between each of the sprite elements and the parent lightning flashes was $\sim 15 \mathrm{~km}$, which is well within our measurement uncertainty and is in agreement with several earlier studies. $38,46,47$

A quasi-linear relationship is observed between the CMC and sprite brightness ${ }^{37,54}$ for the events for which their corresponding Schumann resonance data and parent CG lightning strike were available. The larger the $\mathrm{CMC}$, the larger the electric field generated and the greater the optical signature of the resultant gas discharge.

\section{Conclusion}

Sprites have been photographically recorded for the first time in southern Africa since the earliest sightings reported anecdotally in 1937. We suggest that sprites in southern Africa have the same morphology as those recorded elsewhere and that the CMC of the recorded events agrees with the threshold for dielectric breakdown of the mesosphere. We have also shown that sprite brightness is related quasi-linearly with $\mathrm{CMC}$, as earlier suggested by Yaniv et al. ${ }^{37}$ We plan to observe sprites in future using multiple cameras with filters to extract spectral information and estimate the characteristic energy of the electrons within a sprite.

\section{Acknowledgements}

We acknowledge the financial assistance of the National Research Foundation (South Africa) through grant no. 105535. We also thank the South African Astronomical Observatory, the South African Weather Service and the Climate System Analysis Group, Department of Environmental and Geographical Science, University of Cape Town, for their support.

\section{Authors' contributions}

M.K. was responsible for the conceptualisation, project leadership and project management; S.N., M.K. and P.M. were responsible for the methodology and writing; S.N. and P.M. were responsible for collecting the data; S.N. was responsible for data analysis and sample analysis; J.B. was responsible for charge moment estimation; M.K. and P.M. were responsible for validation, student supervision, funding acquisition.

\section{References}

1. MacKenzie T, Toynbee H. Meteorological phenomena. Nature. 1886:33:245. https://doi.org/10.1038/033245e0

2. Davidson JE. Thunderstorm and aurora phenomena. Nature. 1893;47:582. https://doi.org/10.1038/047582b0

3. Boys CV. Progressive lightning. Nature. 1926;118:749-450. https://doi. org/10.1038/118749a0

4. Wilson CTR. A theory of thundercloud electricity. Proc R Met Soc Lond. 1956;236:297-317. https://doi.org/10.1098/rspa.1956.0137

5. Malan D. Sur les decharges orageuses dans la haute atmosphere [On the stormy discharges in the atmosphere]. Paris: Academie des Sciences; 1937. French.

6. Franz RC, Nemezek RJ, Winckler JR. Television image of large upward electrical discharge above a thunderstorm system. Science. 1990;249:4851. https://doi.org/10.1126/science.249.4964.48

7. Pasko VP, Yair Y, Kuo C-L. Lightning related transient luminous events at high altitude in the earth's atmosphere: Phenomenology, mechanisms, and effects. Space Sci Rev. 2012;168:475-516. https://doi.org/10.1007/ s11214-011-9813-9

8. Siingh D, Singh RP, Singh AK, Kumar S, Kulkarni MN, Singh AK. Discharges in the stratosphere and mesosphere. Space Sci Rev. 2012;169(1-4):73-121. https://doi.org/10.1007/s11214-012-9906-0

9. Pasko VP, Inan US, Bell TF, Taranenko YN. Sprites produced by quasielectrostatic heating and ionization in the lower ionosphere. J Geophys Res. 1997;102(A3):4529-4561.

10. Stanley M, Krehbiel P, Brook M, Moore C, Rison W. High-speed video of initial sprite development. Geophys Res Lett. 1999;26:3201-3204. https://doi. org/10.1029/1999GL010673

11. Stenbaek-Nielsen HC, Kanmae T, McHarg MG, Haaland R. High-speed observations of sprite streamers. Surv Geophys. 2013;34:769-795. https:// doi.org/10.1007/s10712-013-9224-4

12. Sentman DD, Wescott EM, Osborne DL, Hampton DL, Heavner MJ. Preliminary results from the Sprites94 campaign: Red sprites. J Geophys Res Lett. 1995;22:1205-1208. https://doi.org/10.1029/95GL00583

13. Winckler JR, Lyons WA, Nelson T, Nemzek RJ. New high-resolution groundbased studies of cloud-ionosphere discharges over thunderstorms. J Geophys Res Lett. 1999;101:6997-7004. https://doi.org/10.1029/95JD03443

14. Liu NY, McHarg MG, Stenbaek-Nielsen HC. High-altitude electrical discharges associated with thunderstorm and lightning. J Atmos Sol Terr Phys. 2015;136:98-118. https://doi.org/10.1016/j.jastp.2015.05.013

15. Lang TJ, Cummer SA, Rutledge SA, Lyons WA. The meteorology of negative cloud-to-ground lightning strokes with large charge moment changes: Implications for negative sprites. J Geophys Res Atmos. 2013:118:78867896. https://doi.org/10.1002/jgrd.50595

16. Boggs LD, Liu N, Splitt M, Lazarus C, Glenn C, Rassoul H, et al. An analysis of five negative sprite-parent discharges and their associated thunderstorm charge structures. J Geophys Res Atmos. 2016;121(2):759-784. https://doi. org/10.1002/2015JD024188 
17. Fukunishi H, Takahashi $Y$, Uchida A, Sera M, Miyasato KR. Occurrences of sprite and elves above the Sea of Japan near Hukuritku in winter. EOS Supplement. 1999;80:217

18. Neubert T, Rycroft M, Farges T, Blanc E, Chanrion O, Arnone E, et al. Recent results from studies of electric discharges in the mesosphere. Surv Geophys. 2008;29:71-137. https://doi.org/10.1007/s10712-008-9043-1

19. Sao Sabbas FT, Taylor MJ, Pautet PD, Bailey M, Cummer S, Azambuja RR, et al. Observations of prolific transient luminous event production above a mesoscale convective system in Argentina during the Sprite2006 Campaign in Brazil. J Geophys Res. 2010;115, A00E58, 20 pages. https://doi. org/10.1029/2009JA014857

20. Hardman SF, Dowden RL, Brundell JB, Bahr JL, Kawasaki Z, Rodger CJ. Sprite observations in the northern territory of Australia. J Geophys Res. 2000;105(D4):4689-4697.

21. Blanc E, Farges T, Roche R, Brebion D, Hua T, Labarthe A, et al. Nadir observations of sprites from the International Space Station. J Geophys Res Atm. 2004;109, A02306, 8 pages. https://doi.org/10.1029/2003JA009972

22. Jehl A, Farges T, Blanc E. Color pictures of sprites from nondedicated observation on board the International Space Station. J Geophys Res Space Phys. 2013;118:454-461. https://doi.org/10.1029/2012JA018144

23. Sato M, Ushio T, Morimoto T, Kikuchi M, Adachi T, Suzuki M, et al. Overview and early results of the Global Lightning and Sprite Measurements mission. J Geophys Res Atmos. 2015;120:3822-3851. https://doi. org/10.1002/2014JD022428

24. Cummer SA, Inan US, Bell TF, Barrington-Leigh CP. ELF radiation produced by electrical currents in sprites. Geophys Res Lett. 1998;25:1281-1284. https:// doi.org/10.1029/98GL50937

25. Ignaccolo M, Farges T, Mika A, Allin T, Chanrion O, Blanc E, et al. The planetary rate of sprite events. J Geophys Res Lett. 2006;33, L11808, 5 pages. https:// doi.org/10.1029/2005gl025502

26. Ebert U, Nijidam S, Li C, Luque A, Briels T, Van Veldhuizen E. Review of recent results on streamer discharges and discussion of their relevance for sprites and lightning. J Geophys Res. 2010;115, A00E43, 13 pages. https:// doi.org/10.1029/2009JA014867

27. Pasko VP. Recent advances in theory of transient luminous events J Geophys Res. 2010;115(A6), A00E35, 24 pages. https://doi. org/10.1029/2009JA014860

28. Rodger CJ. Red sprites, upward lightning, and VLF perturbations. Rev Geophys.1999;37(3):317-336. https://doi.org/10.1029/1999RG900006

29. Hiraki $Y$, Kasai $Y$, Fukunishi $H$. Chemistry of sprite discharges through ionneutral reactions. Atmos Chem Phys. 2008;8:3919-3928. https://doi. org/10.5194/acp-8-3919-2008

30. Liu N, Dwyer J, Stenbaek-Nielsen H, McJarg M. Sprite streamer initiation from natural mesospheric structures. Nat Comm. 2015;6, Art. \#7540, 9 pages. https://doi.org/10.1038/ncomms8540

31. Yair Y, Peter I, Adam D, Moalem M, Price C, Joachim H, et al. New observations of sprites from the space shuttle. J Geophys Res Lett. 2004;109, D15201, 10 pages. https://doi.org/10.1029/2003JD004497

32. Sato M, Fukunishi H. Global sprite occurrence locations and rates derived from triangulation of transient Schumann resonance events. J Geophys Res Lett. 2003;30(16), Art. \#1859, 4 pages. https://doi.org/10.1029/2003GL017291

33. Chen A, Kuo C, Lee Y, Su H, Hsu R, Chern J, et al. Global distributions and occurrence rates of transient luminous events. J Geophys Res. 2008;113(A8), A08306, 8 pages. http://dx.doi.org/10.1029/2008JA013101

34. Christian H, Blakeslee R, Boccippio D, Boeck W, Buechler D, Driscoll K, et al. Global frequency and distribution of lightning as observed from space by the optical transient detector. J Geophys Res. 2003;108(D1):ACL4-1-ACL4-15. http://dx.doi.org/10.1029/2002JD002347

35. Williams E, Lyons W, Hobara Y, Mushtak V, Asencion N, Boldi R, et al. Groundbased detection of sprites and their parent lightning flashes over Africa during the 2006 AMMA campaign. Q J Roy Meteor Soc. 2010;136(S1):257-271. https://doi.org/10.1002/qj.489

36. Soula S, Van der Velde 0 , Montanyà J, Neubert T, Chanrion 0 , Ganot M. Analysis of thunderstorm and lightning activity associated with sprites observed during the EuroSprite campaigns: Two case studies. Atmos Res. 2009;91(2-4):514-528. https://doi.org/10.1016/j.atmosres.2008.06.017
37. Yaniv R, Yair Y, Price C, Bor J, Sato M, Hobara Y, et al. Ground-based observations of the relations between lightning charge-moment-change and the physical and optical properties of column sprites. J Atmospheric Sol-Terr Phys. 2013;107:60-67. https://doi.org/10.1016/j.jastp.2013.10.018

38. Barrington-Leigh CP, Inan US. Identification of sprites and elves with intensified video and broadband array photometry. J Geophys Res. 2001;106:17411750. https://doi.org/10.1029/2000JA000073

39. Lyons WA. Characteristics of luminous structures in the stratosphere above thunderstorm as imaged by a low-light video. Geophys Res Lett. 1994;21:875-878. https://doi.org/10.1029/94GL00560

40. Kosch M, Pedersen T, Esposito R. Wide angle mirror system design for distortion-less imaging of the sky. Appl 0pt. 2009:48(24):4703-4708. https://doi.org/10.1364/A0.48.004703

41. Collier AB, Hughes AR, Lichtenberger J, Steinbach P. Seasonal and diurnal variation of lightning activity over southern Africa and correlation with European whistler observations. Ann Geophys. 2006;24:529-542. https:// doi.org/10.5194/ange0-24-529-2006

42. Yair Y, Price C, Ganot M, Greenberg E, Yaniv R, Ziv B, et al. Optical observations of transient luminous events associated with winter thunderstorms near the coast of Israel. Atmos Res. 2009;91(2-4):529-537. https://doi. org/10.1016/j.atmosres.2008.06.018

43. Bor J. Optically perceptible characteristics of sprites observed in Central Europe in 2007-2009. J Atmospheric Sol-Terr Phys. 2013:92:151-177. https://doi.org/10.1016/j.jastp.2012.10.008

44. Wescott E, Stenbaek-Nielsen H, Sentman D, Heavner M, Moudry D, SaoSabbas FT. Triangulation of sprites, associated halos and their possible relation to causative lightning and micrometeors. J Geophys Res Space Phys. 2001;106(A6):10467-10477. https://doi.org/10.1029/2000JA000182

45. South African Weather Services (SAWS). South African Weather Service Lightning Detection Network (database on the Internet). No date [cited 2018 Jun 06]. Available from: http://www.weathersa.co.za/observations/lightning

46. Lyons WA. Sprites observations above the USA high plains in relation to their parent thunderstorm systems. J Geophys Res. 1996;101(D23):2964129652. https://doi.org/10.1029/96JD01866

47. Sao Sabbas FT, Sentman DD, Wescott EM, Pinto 0, Mendes 0, Taylor MJ. Statistical analysis of space-time relationships between sprites and lightning. J Atmospheric Sol-Terr Phys. 2003;65(5):525-535. https://doi.org/10.1016/ S1364-6826(02)00326-7

48. Cummer SA, Jaugey NC, Li JB, Lyons WA, Nelson TE, Gerken EA. Submillisecond imaging of sprite development and structure. Geophys Res Lett. 2006;33(4), L04104, 4 pages. https://doi.org/10.1029/2005GL024969

49. Satori G, Szendroi J, Vero J. Monitoring Schumann resonances I: Methodology. J Atmos Terr Phys. 1996;58:1475-1481. https://doi.org/10.1016/00219169(95)00145-X

50. Huang E, Williams E, Boldi R, Lyons W, Taylor M, Nelson T, et al. Criteria for sprites and elves based on Schumann resonance observations. J Geophys Res. 1999;104(D14), 16943-16964. https://doi.org/10.1029/1999JD900139

51. Hobara Y, Hayakawa M, Williams ER, Boldi R, Downes E. Location and electrical properties of sprite-producing lightning from a single ELF site. In: Fullekrug M, Mareev E, Rycroft M, editors. Sprites, elves and intense lightning discharges. NATO science series II: Mathematics, physics and chemistry. Dordrecht: Springer; 2004. p. 211-236. https://doi.org/10.1007/1-40204629-4 10

52. Williams ER, Downes E, Boldi R, Lyons WA, Heckman S. Polarity asymmetry of sprite-producing lightning: A paradox? Radio Sci. 2007;42, RS2S17, 15 pages. https://doi.org/10.1029/2006RS003488

53. Qin J, Celestin S, Pasko VP, Cummer SA, McHarg MG, Stenbaek-Nielsen $\mathrm{HC}$. Mechanism of column and carrot sprites derived from optical and radio observations. Geophys Res Lett. 2013;40:4777-4782. http://dx.doi. org/10.1002/grl.50910

54. Takahashi Y, Yoshida A, Sato M, Adachi T, Kondo S, Hsu R, et al. Absolute optical energy of sprites and its relationship to charge moment of parent lightning discharge based on measurement by ISUAL/AP. J Geophys Res. 2010;115(A9), A00E55, 8 pages. http://dx.doi.org/10.1029/2009JA014814 